\title{
EL DEBATE SOBRE LA ÚLTIMA PALABRA: UN COMPLEJO EQUILIBRIO ENTRE IDENTIDADES CONSTITUCIONALES Y DIPLOMACIA JUDICIAL ${ }^{1}$
}

\author{
THE DEBATE ON THE LAST WORD: A COMPLEX \\ BALANCE BETWEEN CONSTITUTIONAL IDENTITIES \\ AND JUDICIAL DIPLOMACY
}

\author{
Jorge ALEJANDRO AMAYA ${ }^{2}$
}

Recibido: 20/03/2019

Aceptado: 03/05/2019

SUMARIO: I. Introducción; II. El debate histórico sobre la última palabra; III. La aparición de nuevos actores en el debate; IV. Contra-límites, identidad constitucional y diplomacia judicial; V. En el viejo continente: "Taricco"; VI. En el nuevo continente: "Fontevecchia" (MREyC s/cumplimiento de la sentencia Fontevechia y D'Amico c/Argentina); VII. Conclusión final.

SUMMARY: I. Introduction. II. The historical debate on the last word. III. The appearance of new actors in the debate. IV. Counter-limits, constitutional identity and judicial diplomacy. V. In the old continent: "Taricco". VI. In the new continent: "Fontevecchia" (MREyC s/compliance with the judgment Fontevechia and D'Amico c/Argentina). VII. Conclusion.

Resumen: En este trabajo se analiza el complejo equilibrio existente entre las identidades constitucionales y la diplomacia judicial. Llama la atención que en el llamado nuevo constitucionalismo que está preludiando un cambio en la concepción del derecho en donde se ha potenciado la función del juez en la interpretación. Cada Constitución de un país soberano tiene su propia identidad constitucional por lo cual la “diplomacia judicial” en los tribunales, tanto nacionales como internacionales, debe alcanzar el equilibrio necesario como para no alterar la base de la "identidad constitucional” como límite a las decisiones de algunos órganos internacionales.

Abstract: This paper analyses the complex balance between constitutional identities and judicial diplomacy. Attracts our attention that in the so-called new constitutionalism that is preluding a change in the conception of law where the role of the judge in the interpretation it has been enhanced. Each Constitution of a sovereign country has its own constitutional identity whereby "judicial diplomacy" in the courts, both national

\footnotetext{
1 Este artículo forma parte de la ponencia presentada al Congreso Iberoamericano de Derecho Constitucional que se realizará en Facultad de Derecho de la UBA del 21 al 23 de mayo de 2019 y aún no ha sido publicado.

${ }^{2}$ Profesor Ordinario de Derecho Constitucional de la Universidad de Buenos Aires.
} 
and international, must reach the necessary balance so as not to alter the basis of the “constitutional identity” as a limit to decisions of some international bodies.

Palabras claves: Identidad constitucional. Diplomacia judicial. Corte interamericana de Derechos Humanos. Comisión Interamericana de Derechos Humanos.

Key words: Constitutional identity. Judicial diplomacy. Inter-American Court of Human Rights. Inter-American Commission on Human Rights

\section{INTRODUCCIÓN}

En el derecho se llevan a cabo cada tanto grandes transformaciones que modifican instituciones, dando vida a nuevos principios y reglas compatibles con los fines que presiden el cambio o la adaptación del sistema jurídico.

El llamado nuevo constitucionalismo es parte de una realidad que ha provocado un cambio en la concepción del derecho, generando una transformación en el plano de las fuentes que se manifiesta en la pérdida de la centralidad de la ley y de las reglas, sustituyéndose por el papel que adquirieron los principios, los cuales pasaron a funcionar como mandatos vinculantes con operatividad directa.

En este escenario parece haber desaparecido la separación absoluta entre moral y derecho, potenciándose la función del juez en la interpretación y convirtiéndolo en un protagonista estelar del sistema jurídico a través de técnicas que se califican como dinámicas y evolutivas.

La indeterminación, que es propia de los principios, acentuó el papel de los jueces en el proceso de creación del derecho, tornándolos - en muchos casoslegisladores indirectos y también directos.

La finalización de la segunda guerra mundial nos trajo el paradigma de la protección de los derechos humanos y el nacimiento de un sistema de protección de derechos multinivel con la aparición de los sistemas universal y regional de protección de Derechos Humanos; y la modificación de las cláusulas de supremacía constitucional en las constituciones latinoamericanos para dar cabida a una mayor participación del derecho internacional de los derechos humanos en el ámbito de los sistemas jurídicos nacionales.

Los tratados de derechos humanos han pasado a complementar el sistema de protección de los derechos individuales y sociales reconocidos en la parte dogmática de las constituciones, mediante mandatos que vinculan al juez, a la administración, a todos los operadores jurídicos públicos y privados.

Nuevos actores, como la CorteIDH y la ComisiónIDH reclaman para sí una participación decisiva en la interpretación, cumplimiento y garantía de los derechos humanos plasmados en los tratados, que en el caso de Argentina algunos de ellos adquirieron supremacía constitucional a partir de la reforma de 1994 (artículos 75 inciso 22), pasando a complementar el sistema de protección de los derechos individuales y sociales reconocidos en la parte dogmática de nuestra constitución.

En este contexto, la interpretación y protección de los derechos humanos a partir de dos sistemas independientes pero integrados, y cuya palabra final en cada uno de ellos corresponde a distintos órganos, constituye la tarea más difícil que deben 
afrontar los jueces en la actualidad en un clima, como el argentino, en el que impera muchas veces, utilizando palabras de Robert Bork, la seducción política del derecho ${ }^{3}$.

\section{EL DEBATE HISTÓRICO SOBRE LA ÚLTIMA PALABRA}

Hay temas que flotan en el aire de los tiempos. Proyectada esta afirmación al derecho constitucional, bien podríamos decir que el interrogante sobre ¿A quién corresponde la última palabra constitucional? Ha flotado a través del tiempo.

El interrogante encierra - nada más y nada menos - que la toma de posición sobre cuál debe ser el órgano de cierre en un sistema jurídico político completo y complejo como es una democracia constitucional, que se caracteriza por aunar un sistema de gobierno, el gobierno democrático (en principio regido por la regla de la mayoría) y un sistema de estado, el estado constitucional, que erige a la constitución como norma suprema que define la validez o invalidez del resto de las normas del sistema jurídico, y que establece los límites para el ejercicio del autogobierno a través de los derechos y de alguna forma de división en la organización del poder ${ }^{4}$.

El primer antecedente jurídico del debate sobre la última palabra más enfatizado por la doctrina ${ }^{5}$, es el caso Bonham de 1610 y proviene - curiosamente - de Inglaterra, un país con constitución consuetudinaria no escrita y sin control de constitucionalidad.

Este precedente judicial ha sido considerado por muchos, desde un punto de vista jurídico-formal, como la raíz del control de constitucionalidad en razón del paralelismo que el Juez Coke formuló situando al common law por encima del Parlamento, atribuyendo a aquel un carácter de fundamental law del ordenamiento inglés, a través del cual se permitiría a los jueces controlar los actos del Parlamento. El significado de ésta decisión como verdadero germen del control jurisdiccional de constitucionalidad, sin embargo, no ha estado exento de refutación ${ }^{6}$.

Casi dos siglos después (1803) se dicta el célebre fallo de la Corte Suprema de los Estados Unidos "Marbury v. Madison"7, que se conoce públicamente como el

\footnotetext{
${ }^{3}$ The tempting of America, The political seduction of the law, The Free Press, 1990.

${ }^{4}$ Amaya, Jorge Alejandro, Democracia y Minoría Política, Astrea, Buenos Aires, 2014.

${ }^{5}$ Se puede profundizar sobre este caso en varios trabajos, entre ellos Ferrer Mac Gregor, Eduardo, "El control difuso de convencionalidad en el Estado Constitucional"; Rey Martínez Fernando, "Una relectura del Bonham Case y de la aportación de Sir Edward Coke a la creación de la judicial review", ambas en UNAMm Biblioteca Virtual, www.juridicas.unam.mx; Vázquez Rizo, Ana M., "El caso Bonham. Supremacía Constitucional”, Universidad del Norte, Revista de Derecho № 11, p. 137/140, Colombia, 1999.

${ }^{6}$ En efecto, conforme revela Acosta Sánchez, diversos problemas suscitados en aquél pasaje, incluso acerca de los precedentes que Coke utilizó, fueron investigados por constitucionalistas norteamericanos e ingleses, los cuales han concluido que "no hay base histórica sólida para hallar ningún tipo de precedente de la judicial review en la práctica británica”, ya que los jueces reconocían el rango superior del statute aprobado por el Parlamento "y la universal obediencia debida al mismo, ver Acosta Sánchez José, "Formación de la Constitución y jurisdicción constitucional: fundamentos de la democracia constitucional”, Tecnos, Madrid, 1998, p.93.p. 36.

${ }^{7}$ Se han escrito gran cantidad de obras, trabajos y ensayos sobre este fallo, además de nuestro libro citado
en nota anterior. Entre otros pueden verse Clinton Robert L., "Marbury vs. Madison, and the Judicial
Review, University Press of Kansas, 1989; William E. Nelson, "Marbury v. Madison: The Origins and
Legacy of Judicial Review", University Press of Kansas, 2000; M Cueva Fernández Ricardo, "De los
niveladores a Marbury vs. Madison. La génesis de la democracia constitucional”, Centro de Estudios
} 
origen del control judicial difuso de constitucionalidad, el cual deposita una confianza casi irrestricta en los jueces y esparció su influencia por toda América, con especial fortaleza en el sistema constitucional argentino que replicó Marbury en Sojo ${ }^{8}$ y Elortondo ${ }^{9}$.

La importancia de la sentencia dictada por la Corte Suprema de los Estados Unidos radica en que en ella declaró que la disposición de una ley era nula porque era contraria al texto de la Constitución; y que ese poder de declarar la invalidez de una ley cuando era contraria a la Constitución, es de la verdadera esencia del Poder Judicial, asignando a los jueces la última palabra constitucional.

A principios del siglo XX recrudece nuevamente el debate en torno a la última palabra constitucional en el famoso enfrentamiento dialéctico entre Hans Kelsen y Carl Schmitt, que finalmente legó el diseño que Kelsen planteara en su propuesta de "Tribunal Constitucional” y que tuviera sus primeros reflejos en las Constituciones de Checoslovaquia y Austria.

Este modelo conocido como concentrado o especializado, deposita la última palabra en un órgano fuera del Poder Judicial, y está hoy vigente en la mayoría de los países europeos y en algunas naciones latinoamericanas ${ }^{10}$.

Sin olvidar el modelo político francés, con sus particularidades, que centra la última palabra constitucional en un órgano de naturaleza esencialmente política (el Consejo Constitucional Francés) - hoy atemperadas por la reforma constitucional francesa del año 2008 - el modelo de “Tribunales Constitucionales” y la “judicial review”, son los han atrapado con mayor fuerza el interés del mundo occidental.

Por supuesto que el tiempo y la evolución del control han hecho que los modelos se hayan acercado, e incluso fusionado muchas de sus características originales, particularmente en los sistemas de control que cada país ha implementado a través de sus constituciones o incluso a través de la interpretación jurisprudencial.

Políticos y Constitucionales, Madrid, 2011; Arguing, “Marbury V. Madison”, Editor Tushnet, Mark V, Stanford University Press; Manili Pablo (coordinador), "Marbury vs. Madison. Reflexiones sobre una sentencia bicentenaria”, Editorial Porrúa, México 2011; Miller Jonathan M.; Gelli María Angélica, Cayuso Susana, “Constitución y Poder Político”, Tomo 1, Editorial Astrea, Buenos Aires, 1987, p. 5/12; Valdés S. Clemente, "Marbury vs. Madison. Un ensayo sobre el origen del poder de los jueces en EEUU”, Revista del Instituto Iberoamericano de Derecho Procesal Constitucional $\mathrm{N}^{\circ}$ 5, enero-junio de 2006; Trionfetti, Víctor, "Marbury a contraluz", Suplemento de Derecho Constitucional La Ley, 1/01/2009; Sanin Restrepo, Ricardo, “En nombre del pueblo. Destruyendo a Marbury”, Revista Criterio Jurídico, Cali, Colombia, Volúmen 6, p. 61/92; Haro Ricardo, “Marbury v. Madison”: El sentido constituyente y fundacional de su sentencia”, Academia Nacional de Derecho y Ciencias Sociales de Córdoba, 2003; Aragón Navarro Carlos, “Marbury v. Madison. Los límites de la Corte”, Regímenes Constitucionales contemporáneos (2008); Carbonell Miguel, "Marbury versus Madison: en los orígenes de la supremacía constitucional y el control de constitucionalidad”, Revista Iberoamericana de Derecho Procesal Constitucional $N^{\circ}$ 5», Eduardo Ferrer Mac-Gregor (director), Editorial Porrúa, Instituto Iberoamericano de Derecho Procesal Constitucional, México, 2006, pp. 295; Eto Cruz Gerardo, “”John Marshall y la sentencia Marbury vs. Madison”, en Ferrer Mac-Gregor, Eduardo (coordinador), Derecho Procesal constitucional, $4^{\circ}$ edición, Porrúa, México-SCJN, tomo I, 2003.

${ }^{8}$ Corte Suprema Argentina 22/09/1887.

${ }^{9}$ Corte Suprema Argentina 14/04/1888.

10 Kelsen, Hans, La garantía jurisdiccional de la Constitución (la justicia constitucional), "Revista Iberoamericana de Derecho Procesal Constitucional”, $\mathrm{n}^{0}$ 10, p. 3; Schmitt, Carl La defensa de la Constitución, prólogo de Pedro de Vega, Editorial Tecnos, 1983; Kelsen, Hans ¿Quién debe ser el defensor de la Constitución?, Editorial Tecnos, 1995. 
La idea de Constitución como norma básica o referencial, es central en ambos modelos. Precisamente en esta característica radica su supremacía, ya que el resto de las normas que integran el ordenamiento derivan su validez de la constitución que es fundadora, básica o referencial.

Así, los derechos, la limitación del poder, y el órgano encargado de garantizar los mismos a través del ejercicio de adecuación de la norma inferior a la superior declarando su invalidez en caso de oposición para preservar el principio de supremacía constitucional, fue el motor fundamental de las luchas del constitucionalismo por un orden más justo.

\section{LA APARICIÓN DE NUEVOS ACTORES EN EL DEBATE}

La catástrofe mundial que significó la Segunda Gran Guerra legó a la sociedad mundial un cambio de paradigma: un nuevo orden caracterizado por la internacionalización de los derechos en los ámbitos regionales y en el universal.

Esto provocó la apertura del derecho constitucional y su integración con el derecho internacional para dar nacimiento por un lado al llamado derecho de los derechos humanos.

Esta última situación se materializó en las constituciones a través de cláusulas "puente", es decir de normas que han integrado los sistemas jurídicos nacional y regional e internacional, a través de modificaciones en los principios de supremacía constitucional incorporando en sus sistemas formales de fuentes al derecho internacional, particularmente a las normas internacionales sobre derechos humanos ${ }^{11}$.

La Constitución argentina había configurado su cláusula de supremacía a través de los artículos 31 y 27. Por artículo 31 "La Constitución, las leyes de la Nación que en su consecuencia se dicten por el Congreso y los tratados con potencias extranjeras son ley suprema de la Nación...", y de acuerdo al 27 "El gobierno federal está obligado a afianzar las relaciones de paz y comercio con las potencias extranjeras por medio de tratados que estén de conformidad con los principios de derecho público establecidos en la constitución”.

Con el retorno de la democracia en 1983, Argentina ratificó por ley - al año siguiente - la Convención Americana de Derechos Humanos (CADH) y en 1992 la CSJN en el caso Ekmekdjian c/Sofovich ${ }^{12}$, en el cual se discutió la operatividad del art. 14 de la CADH sobre derecho de rectificación o respuesta, el Alto Tribunal - haciendo hincapié en el art. 27 de la Convención de Viena ratificada por argentina en 1972 - dijo que esta norma obligaba al país a dar preeminencia a los tratados internacionales. Esta doctrina fue ratificada en las causas Fibraca Constructora (1993) ${ }^{13}$ y Cafés la Virginia $(1994)^{14}$.

Estos importantes fallos inspiraron uno de los puntos de ley declarativa de la reforma constitucional de 1994 (artículo $3^{\circ}$ de la ley 24.309) que habilitó la "incorporación de institutos de integración regional y de jerarquía de los tratados internacionales”.

\footnotetext{
11 Sobre este desarrollo véase la obra Pizzolo, Calogero, Comunidad de intérpretes finales, Astrea, Buenos Aires, 2017.

12 CSJN sentencia del 07/07/1992.

${ }^{13}$ CSJN sentencia del 07/07/1993.

${ }^{14}$ CSJN sentencia del 13/10/1994.
} 
Esta habilitación originó el actual inciso 22 del art. 75 CN que consagra en el primer párrafo “que los tratados y concordatos tienen jerarquía superior a las leyes” y en el segundo se enumeran diez tratados y declaraciones de derechos humanos, afirmando que "en las condiciones de su vigencia, tienen jerarquía constitucional, no derogan artículo alguno de la primera parte de esta Constitución y deben entenderse complementarios de los derechos y garantías por ella reconocidos”.

Esta cláusula fue la generadora del concepto de "bloque de constitucionalidad federal" (siguiendo el derecho francés) como conjunto normativo integrado por la Constitución y los tratados y declaraciones internacionales que están fuera de la constitución, pero que poseen jerarquía constitucional. Este concepto fue tomado literalmente por la Corte Suprema en el caso Álvarez en el año $2010^{15}$.

Doctrina y jurisprudencia han debatido sobre la interpretación de la cláusula en torno a distintos alcances de los conceptos de "jerarquía constitucional”; "en las condiciones de su vigencia" y que "no derogan artículo alguno de la primera parte de esta Constitución y deben entenderse complementarios de los derechos y garantías por ella reconocidos".

La cuestión no es meramente semántica o académica, sino que las consecuencias derivadas de la posición que se adopte al respecto implican dar diversas soluciones al planteo, cuyo análisis excede el núcleo de este trabajo.

Por consiguiente los tribunales argentinos - a partir de la ratificación legislativa de la Convención Americana de Derechos Humanos (CADH) acaecida en 1984 y de la reforma de 1994 poseen doble fuente normativa para realizar las interpretaciones judiciales de los derechos, generándose además la necesidad de integrar la jurisprudencia nacional a la jurisprudencia internacional emanada de los órganos creados por la CADH: La Corte IDH, órgano jurisdiccional, que se expresa a través de su función judicial y consultiva; y la ComisiónIDH, órgano político, que se expresa a través de recomendaciones a los estados y como llave de apertura de la jurisdicción de la Corte.

Así, ha aparecido en la escena de la última palabra un nuevo actor protagónico que, en pocos años, ha reclamado para sí un rol principal en dicho debate.

La CorteIDH ha ido perfilando - con gran activismo - lo que ha dado en llamar el control de convencionalidad, una creación pretoriana del Tribunal Internacional que actúa en forma similar al control de constitucionalidad, al cotejar las normas internas con las normas internacionales provenientes de la CADH y del llamado "corpus iuris internacional o interamericano" ${ }^{16}$, y comenzó depositando esta tarea (que ejerce ella en forma concentrada) de manera difusa en todos los jueces latinoamericanos, para extenderla rápidamente a todos los órganos del poder público de los países integrantes del sistema ${ }^{17}$, pretendiendo que la "ratio decidendi" o el "holding" de sus fallos resulten

\footnotetext{
15 CSJN sentencia del 07/12/2010.

${ }^{16}$ Esta expresión ha sido una contribución de la CorteIDH. El concepto fue definido por primera vez en la Opinión Consultiva OC-16/1999.

${ }^{17}$ Este instituto tiene su origen en un voto individual del Juez Sergio García Ramírez en el caso Myrna Mac Chang c/ Guatemala ${ }^{17}$ y es adoptado por el Tribunal en pleno en el conocido caso Almonacid Arellano c/ Chile ${ }^{17}$, sosteniendo en el parágrafo $\mathrm{N}^{0} 124$ de la sentencia que el Poder Judicial debe ejercer una especie de Control de convencionalidad entre las normas jurídicas internas que aplican en los casos concretos y la CADH, y que en esta tarea debe tenerse en cuenta no solo el tratado sino también la interpretación que del mismo ha hecho la CorteIDH, interprete última de la CADH. Tres meses después en Trabajadores Cesados del Congreso c/ Perú ${ }^{17}$, profundiza este aspecto sosteniendo que el Poder Judicial debe ejercer no solo control de constitucionalidad sino también de convencionalidad y que esto
} 
vinculantes para los jueces interamericanos a los efectos del control de convencionalidad en el marco de sus competencias y reglas procesales, lo que resulta asimilable al efecto de la jurisprudencia en los sistemas anglosajones (doctrina del stare decisis).

Así, el control de convencionalidad se ha perfilado como un control de supraconstitucionalidad en temas de derechos humanos, ya que en caso que alguna disposición constitucional fuera contraria a la Convención, según la interpretación de la Corte, el Estado estaría obligado a modificar la Constitución como sucedió con la República Chile en el caso de la Última Tentación de Cristo ${ }^{18}$, llegando a sostener incluso - que la sola existencia de un régimen democrático no garantiza per se el respeto del derecho internacional de los Derechos Humanos, y que la aprobación popular en una democracia de una ley incompatible con la $\mathrm{CADH}$ no le concede legitimidad ante el derecho internacional ${ }^{19}$.

Ciertamente la CorteIDH, como tribunal internacional, no solo es el último intérprete del SIDH, sino que reclama hoy para sí la última palabra constitucional en el derecho interno de los países, cuando el mismo confronta con la $\mathrm{CADH}$, situación que pone frente a frente (en muchos casos) al tribunal internacional y a los tribunales internos de los países del Sistema Interamericano.

\section{CONTRA-LÍMITES, IDENTIDAD CONSTITUCIONAL Y DIPLOMACIA JUDICIAL}

¿Es posible hoy sostener una desintegración parcial del orden internacional mundial como un fenómeno visible? ¿Puede verse esta afirmación en fenómenos políticos como el declive relativo de Estados Unidos (potencia hegemónica de las últimas décadas y principal valedor del orden multilateral)?

¿Puede derivarse dicho interrogante de crisis como las que vive Ucrania, Irak, Siria o España? ¿O las actuales tensiones entre Italia, Francia y Alemania alrededor de la política migratoria europea? ¿O el fenómeno del desmembramiento del orden económico multilateral ejemplificado en el Brexit? ${ }^{20} \dot{ } \mathrm{O}$ la aparición de populismos en Latinoamérica y Europa que destacan y reafirman los nacionalismos? La interacción entre las Altas Cortes Internacionales y las Nacionales no escapa a esta realidad política, jurídica y social.

Es que si bien existen rasgos clásicos del Constitucionalismo, que se caracteriza por su aspiración por la limitación del poder público, lo cierto es que la procesos de consagración del constitucionalismo y la construcción de las constituciones en cada país, responden a razones históricas, sociales, institucionales y hasta económicas propias, que depositan además una impronta o idiosincrasia particular en el ejercicio del poder constituyente originario y en el derivado.

debe efectuarse de oficio en el marco de las respectivas competencias y las regulaciones procesales correspondientes. En Cabrera García y Montiel Flores c/México la CorteIDH ${ }^{17}$ avanza aún más con la obligación del control de convencionalidad extendiéndolo a todos los órganos vinculados con la administración de justicia en todos los niveles; y posteriormente en Gelman c/ Uruguay ${ }^{17}$ lo extiende a cualquier autoridad pública ${ }^{17}$.

${ }^{18}$ CorteIDH sentencia del 15/01/1999.

19 Caso Gelman c/Uruguay (2011 y 2013).

${ }^{20}$ STEINBERG, FEDERICO “La desintegración del orden internacional” pub. 06.10.14 en ElPais.com. 
Si asumimos esta tesis, cada Constitución de un país soberano tiene su propia identidad constitucional, un núcleo mínimo o duro que la distingue y la preserva. Por supuesto, delinear la identidad constitucional es un reto para la teoría constitucional moderna, ya que siempre encierra el riesgo de que sirva para justificar una era de fuertes nacionalismos, por lo cual no debe confundirse la identidad constitucional, que se enmarca dentro de la teoría constitucional, con la identidad nacional que se encuadra en la ciencia política y en la sociología jurídica.

Por ejemplo, Klug Heinz ${ }^{21}$ refiere que la identidad constitucional surge de una manera dialógica y representa una mezcla de aspiraciones políticas y compromisos que son expresión del pasado de una nación, así como la determinación de aquellos escollos que la sociedad busca trascender de dicho pasado.

Por su parte Ackerman ${ }^{22}$, entiende que la identidad constitucional se halla en la dialéctica de los valores defendidos en el pacto fundacional y los valores que han ido abrigando los ciudadanos a través del tiempo. Se construye a través de un camino dialógico entre los valores del pasado con los principios del presente.

Por estas razones, la identidad constitucional está compuesta por los principios y los valores fundacionales, a los que se les otorga un contenido histórico y político que determinó la existencia misma de las Constituciones, y que se reconstruyen en el trayecto histórico y sociológico de un país.

Se entabla una dialéctica entre los principios fundantes y los presentes para poseer una identidad constitucional. No se pretende que la Constitución zanje las controversias sociales fundamentales, porque si bien representa valores fundantes también contiene acuerdos teóricos incompletos.

En este contexto, la noción de identidad constitucional ha actuado principalmente con dos efectos limitantes: uno interno y otro externo.

El interno ha operado sobre las reformas constitucionales; el externo sobre algunas decisiones de los órganos internacionales. Es, en este último caso, la aplicación de la teoría de los contra límites, desarrollada con gran fuerza por la jurisprudencia y la doctrina Italiana.

La identidad de la constitución como límite a las reformas, está directamente relacionado con la estabilidad jurídico política de los Estados y remite a la temática de los límites materiales e internacionales $\mathrm{y}$ al control de constitucionalidad y convencionalidad de las reformas constitucionales. Se parte de sostener la existencia de un núcleo intangible, tema que ha sido muy estudiado por el constitucionalismo alemán e italiano, y otros países como Colombia o la India.

La identidad constitucional como límite a algunas decisiones de los órganos internacionales, ha estado presente en últimas decisiones de la Corte Constitucional Italiana y de la Corte Suprema de la Nación Argentina.

En el contexto descripto, la relación inevitable (al menos hasta hoy) entre las cortes internacionales y las nacionales, ha sido referida de diferente manera: "diálogo jurisdiccional”, “contra-límites”, "identidades constitucionales”, "esferas de reserva soberana”, “protecciones multinivel”, “margen de apreciación nacional”. Todas ellas

\footnotetext{
${ }^{21}$ Klug, H. (2011). Constitutional identity and change. Tulsa Law Review, 47, 40-49. Disponible en: http://digitalcommons.law.utulsa.edu/cgi/viewcontent.cgi?article=2760\&- context=tlr

${ }^{22}$ Ackerman, Bruce We the people way I. Fundamentos de la historia constitucional estadounidense. Ecuador: Instituto de Altos Estudios del Ecuador (2015)..
} 
ponen el foco en la relación entre los tribunales nacionales e internacionales, pero desde distinta perspectiva.

En lo que respecta a este trabajo, hemos incorporado al concepto de “identidades constitucionales" (referido precedentemente) y también el de "diplomacia judicial" 23 , la cual se centra no en hacer valer la autoridad por la autoridad misma sino por el peso propio de la argumentación, pero no solo de la argumentación desde la perspectiva exclusivamente jurídica, sino también desde su perspectiva política, ya que el control de constitucionalidad-convencionalidad es un acto claramente jurídicopolítico.

Así, asumida la tensión entre las decisiones de las cortes internacionales y las nacionales, el definir "quién tiene la última palabra” en los procesos jurisdiccionales donde confluyen sistemas jurídicos integrados, es evidentemente una contienda no sólo jurídica, sino eminentemente política.

Dos casos judiciales traemos como ejemplo y aval de nuestras afirmaciones: uno Europeo y otro Latinoamericano, dejando a salvo, por supuesto, las diferencias jurídicas y políticas entre la conformación de los sistemas europeo e interamericano.

\section{EN EL VIEJO CONTINENTE: “TARICCO”}

En este caso (que comprendió dos fases) ${ }^{24}$ se subordinó el cumplimiento de una obligación comunitaria a la no vulneración del principio de legalidad penal.

La Sentencia está precedida por una cuestión prejudicial planteada por la Corte Costituzionale italiana (CCI), en la que esta mostraba -suaviter in modo fortiter in re- sus dudas de interpretación acerca de una obligación comunitaria (leída a la luz de Taricco $^{25}$ ) que choca con la tutela de un derecho fundamental inalienable y núcleo de la identidad constitucional italiana.

El caso “Taricco" muestra la contienda entre el principio de primacía del Derecho de la Unión y el parámetro de tutela de los derechos fundamentales marcado por la Constitución nacional; o, si se prefiere, la que se produce cuando el estándar o parámetro nacional, más protector que el europeo-comunitario, se opone al cumplimiento de alguna obligación comunitaria.

El caso comenzó con la sentencia del Tribunal de Justicia de la Unión Europea (TJUE) de fecha 08/09/15 en el expediente “Taricco y otros”, en la que se afirmó la incompatibilidad de la normativa italiana relativa a la interrupción y los plazos máximos de prescripción de los delitos, con el principio fundamental del deber de cooperación leal (art. 4, apdo. 3, TUE) porque era incapaz de tutelar de forma suficientemente adecuada los intereses financieros de la Unión.

La CCI se encontró con la disyuntiva de conformarse al criterio del TJUE u oponerse a la primacía del derecho de la UE. Buena parte de los juristas italianos le

\footnotetext{
${ }^{23}$ Ver en Italia Di tommaso, EMILIO EPIDENDio "Prescrizione, legalità e diritto giurisprudenziale: la "crisi" del diritto penale tra le corti" en https://www.penalecontemporaneo.it/upload/7373epidendio2017a.pdf; en España Di TOMMASO, EMILIO EPIDENDIO "Prescrizione, legalità $e$ diritto giurisprudenziale: la "crisi" del diritto penale tra le corti" en https://www.penalecontemporaneo.it/upload/7373-epidendio2017a.pdf

${ }^{24}$ STJ as. Procedimiento penal c. M.A.S. Y M.B. (C-42/17)

${ }^{25}$ C-105/14, EU:C: 2015:555 (TARICCO I).
} 
reclamaba a la CCI - y algunos con mucha fuerza como Luciani $^{26}$ - la aplicación de contra-límites ante la violación del principio de legalidad en materia penal, consagrado por el art. 25 inciso 2 de la Constitución Italiana ${ }^{27}$.

La CCI sometió nuevamente al TUE - en fecha 27/01/17- una consulta indicativa de cuál era su preferencia en cuanto a la pertenencia de Italia a la Unión y el respeto a los principios estructurales de su ordenamiento interno.

Este giro resultó un verdadero intento de diálogo judicial diplomático con el TJUE y a la vez, una promesa de límite, tratando de demostrar la deferencia hacia el derecho de la Unión, y reiterando su posición de garante supremo de los principios conformantes de la esfera de reserva soberana italiana.

El núcleo técnico de la disputa entre los dos tribunales radicaba en que la CCI subrayó que en el ordenamiento jurídico italiano el plazo de prescripción se encontraba dentro del ámbito de aplicación del principio de legalidad en los delitos penales, sosteniendo que en Italia el período de limitación es parte del derecho penal sustancial y no puede ser excluido de la garantía contra cambios post factum en detrimento de la persona acusada.

Sosteniendo además que el principio de legalidad en los delitos penales, en todos sus aspectos, es decir, incluido el período de limitación, debe considerarse un principio supremo de la Constitución Italiana, que prevalece sobre la legislación de la UE en conflicto.

La CCI en los fundamentos de la decisión $N^{0}$ número 115/2018 del 31/05/18 concluyó con la deferencia a la primacía del derecho nacional.

\section{EN EL NUEVO CONTINENTE: “FONTEVECCHIA" (MREYC S/CUMPLIMIENTO DE LA SENTENCIA FONTEVECCHIA Y D'AMICO C/ARGENTINA) ${ }^{28}$}

Este fallo bien puede ser considerado uno de los primeros y más elocuentes diálogos entre la CSJN Argentina y la CorteIDH, un verdadero caso de "identidad constitucional” y “diplomacia judicial”.

El 14 de febrero de 2017 la CSJN falló en los autos Ministerio de Relaciones Exteriores y Culto s/ Informe sentencia dictada en el caso Fontevecchia y D'Amico v. Argentina por la Corte Interamericana de Derechos Humanos, desestimando la presentación de la Dirección de Derechos Humanos del Ministerio de Relaciones Exteriores y Culto por la cual se solicitaba que, como consecuencia del fallo de la Corte Interamericana dictado en la causa Fontevecchia se dejara sin efecto una sentencia firme de la Corte Suprema.

La posición mayoritaria fue conformada por el voto conjunto de los jueces Lorenzetti, Highton y Rosenkrantz (último ministro en incorporarse a la renovación parcial del Tribunal) y el voto propio del juez Rosatti, habiendo disentido el juez Maqueda.

El voto conjunto consideró que no correspondía hacer lugar a lo solicitado en tanto ello supondría transformar a la Corte IDH en una "cuarta instancia” revisora de los

\footnotetext{
${ }^{26}$ Sostenía Luciani que no debía temer la CCI iniciar una guerra contra el TJUE. LUCIANI, M. "Il brusco risveglio. I controlimiti e la fine mancata della storia costituzionale”. (2016). Rivista Aic.it, 2, 1-20.”

${ }^{27}$ Según el art. 25.2 Const.it.: "Nessuno può essere punito se non in forza di una legge che sia entrata in vigore prima del fatto commesso".

${ }^{28}$ Fallos 324:2895
} 
fallos dictados por los tribunales nacionales, en contravención de la estructura del sistema interamericano de derechos humanos y de los principios de derecho público de la Constitución Nacional Argentina.

En este sentido, entendió que el texto de la Convención no atribuye facultades a la Corte Interamericana para ordenar la revocación de sentencias nacionales (art. 63.1, C.A.D.H.). Asimismo, consideró que revocar su propia sentencia firme — lo que según la CSJN surgía de lo dispuesto por la sentencia de la CorteIDH - implicaría privarla de su carácter de órgano supremo del Poder Judicial Argentino y sustituirla por un tribunal internacional, en violación a los arts. 27 y 108 de la Constitución Nacional.

El juez Rosatti en su fundamentos identificó la llamada esfera de reserva soberana (los principios del derecho público a los que alude el art. $27 \mathrm{CN}$ ) a la que alude el voto mayoritario, con un margen de apreciación nacional de la Corte Suprema en la aplicación de las decisiones internacionales (con base en los arts. 75 inc. 22 y 27 de la Constitución Nacional).

Asimismo, referenció al “diálogo jurisprudencial” para maximizar la vigencia de los derechos en juego sin afectar la institucionalidad, afirmando que la Corte Interamericana de Derechos Humanos es la máxima intérprete de la Convención Americana sobre Derechos Humanos y la Corte Suprema de Justicia de la Nación es la máxima intérprete de la Constitución Nacional, por lo que hay que lograr que sus criterios -en cada caso concreto- se complementen y no colisionen.

En la disidencia, el juez Maqueda mantuvo la postura fijada en sus votos en los casos "Cantos” (2003), "Espósito” (2004), "Derecho” (2011), “Carranza Latrubesse” (2013) y "Mohamed" (2015), según la cual - a partir de la reforma constitucional de 1994 - las sentencias de la CorteIDH dictadas en causas en que la Argentina es parte deben ser cumplidas y ejecutadas por el Estado y, en consecuencia, son obligatorias para la Corte Suprema de Justicia de la Nación, resolviendo dejar sin efecto la sentencia de la Corte Suprema de Justicia de la Nación de 2001 que había condenado a los periodistas Jorge Fontevecchia y Héctor D’Amico por publicaciones realizadas en la prensa, dado que la Corte Interamericana había resuelto en 2011 que esa sentencia constituía una violación al derecho a la libertad de expresión reconocido en el Pacto de San José de Costa Rica (art. 13).

La doctrina del Alto Tribunal, en lo que ha este trabajo refiere, podría resumirse de la siguiente forma:

El constituyente ha consagrado en el art. 27 CN una "esfera de reserva soberana” (identidad constitucional) delimitada por los principios de derecho público establecidos en la Constitución, a los cuales los tratados internacionales deben ajustarse y con los cuales deben guardar conformidad.

Estos principios ubican a la CSJN, vía interpretación constitucional, como el tribunal que posee la última palabra en el resguardo de la "esfera de reserva soberana", ya que revocar una sentencia firme dictada por el Tribunal implicaría privarlo de su carácter de órgano supremo del Poder Judicial argentino, sustituyéndolo por un tribunal internacional.

Posteriormente, en fecha 18/10/2017 la CorteIDH dictó su sentencia de supervisión de cumplimiento de la causa "Fontevecchia".

Allí dijo - en un claro ejemplo de diplomacia judicial - que para dar cumplimiento a la reparación de "dejar sin efectos" (que había sido interpretado por el Tribunal Nacional como sinónimo de “revocar”) los Estados habían adoptado 
históricamente diferentes tipos de medidas o acciones y lo habían comunicado a la Corte, la cual realizaba una valoración en cada caso concreto.

Que tratándose de una sentencia civil (que no queda constando en registros de antecedentes de delincuentes) el Estado Argentino podía adoptar algún otro tipo de acto jurídico, diferente a la revisión de la sentencia, para dar cumplimiento a la medida de reparación ordenada, como por ejemplo la eliminación de su publicación en las páginas web de la Corte Suprema de Justicia o que se mantuviera su publicación pero se realizara algún tipo de anotación indicando que la sentencia había sido declarada violatoria de la $\mathrm{CADH}$ por la CorteIDH.

Esta interesante invitación del tribunal internacional fue rápidamente aceptada por la Corte Argentina - en un nuevo ejemplo de diplomacia judicial - quien en fecha 05/12/2017 dictó una resolución que dispuso ordenar que se asentara que la sentencia del caso que había motivado el acceso al SIDH por parte de los periodistas había sido fue declarada incompatible con la CADH por la CorteIDH.

La sentencia presenta un interrogante mayor: ¿Cuáles son los principios de derecho público contenidos en el art. $27 \mathrm{CN}$ que actúan como "esfera de reserva soberna”?

Solo como referencia y para no exceder la misión de este artículo, consideramos que los principios de derecho público del art. 27 pueden ser analizados desde tres perspectivas: la institucional (división de poderes, régimen federal); la ideológica (los valores y principios propios de cada Nación); y la del núcleo de sus derechos fundamentales ${ }^{29}$.

\section{CONCLUSIÓN FINAL}

La interconexión de los sistemas nacionales con los internacionales ha traído enormes avances a la humanidad y a la persona como centro y finalidad del derecho; y la expectativa de un ius comune regional e incluso universal a construir mediante la cooperación prudente y responsable de todos los actores.

Pero más allá del perfeccionamiento de los diseños jurídicos interconectados; o de los mejores esfuerzos interpretativos que se formulen a través de la diplomacia judicial frente a las tensiones con las identidades constitucionales, el debate sobre la última palabra siempre parece estar presente.

29 “Los principios de derecho público de la Constitución son los que conforman su techo ideológico y se manifiestan en los derechos personales y en la estructura básica del poder” y remite a la ideología y valores de la constitución SAGÜES, NÉSTOR PEDro “Manual de derecho constitucional”, Ed. Astrea, Bs. As., 2016, p. 418 y 131 Y SS. 